\title{
CRIAÇÃO DE EMPRESAS E OS ELEMENTOS EMPREENDEDORES
}

\author{
COMPANY CREATION AND ENTREPRENEURIAL ELEMENTS
}

\author{
Recebido: 18/01/2018 - Aprovado: 29/6/2018 - Publicado: 30/7/2018 \\ Processo de Avaliação: Double Blind Review
}

\author{
Sara Fernandes Picheth ${ }^{1}$ \\ Doutoranda em Administração da Universidade Estadual de Maringá- UEM \\ sarafpicheth@gmail.com
}

\begin{abstract}
RESUMO: Diante da grande importância atribuída ao estudo do empreendedorismo no meio acadêmico, este artigo tem por objetivo analisar o passo anterior à personificação do empreendedorismo na sociedade, isto é, a criação de empresas. Buscou-se responder as seguintes questões: quais os processos envolvidos nessa etapa? Quais variáveis devem ser abordadas? E como ocorre esse processo? Para tanto, foi realizada uma revisão bibliográfica com dados secundários de alguns dos principais autores do campo que trabalharam o tema proposto. Com base no referencial exposto, pôde-se observar que, apesar de o processo de criação ser um tema de grande importância no campo de empreendedorismo, proporcionando geração de valor ao mercado, o mesmo, assim como seu campo de um modo geral, apresenta-se altamente fragmentado. Abordagens divergentes e independentes sobre o mesmo assunto contribuem para essa fragmentação. Assim, a partir dos resultados já conquistados, torna-se mais necessário para as próximas pesquisas a busca por uma maior coesão dos estudos, a fim de neutralizar as diversas fragmentações do campo e erradicar as lacunas existentes.
\end{abstract}

Palavras-chave: empreendedorismo; criação de empresas; elementos empreendedores.

ABSTRACT: According to the huge importance which is given to the study of entrepreneurship in the academic field, this article aims at analyzing the previous step to the personification of entrepreneurship in society, which is, the creation of companies. This research intends, mainly, to answer the following questions: what are the processes involved in this stage? Which variables should be addressed? And how does this process occur? In order to answer those, a bibliographic review was carried out with secondary data of some of the main authors in the field that have worked on the proposed theme. Based on the aforementioned referential, it was observed that, although the creation process is a topic of great importance in the field of entrepreneurship, providing value generation to the market, it is, as well as its field in general, highly fragmented. Divergent and independent approaches on the same subject contribute to this fragmentation. Thus, from the results already achieved, it has become more necessary for the next researches, to look for a greater cohesion of the studies in order to neutralize the diverse fragmentations in the field and to eradicate the existent gaps.

\footnotetext{
${ }^{1}$ Autor para correspondência: Universidade Estadual de Maringá- Av. Colombo, 5790 - Zona 7, Maringá PR, 87020-900, Brasil.
}

REMIPE- Revista de Micro e Pequenas Empresas e Empreendedorismo da Fatec Osasco 
REMIPE

Keywords: entrepreneurship; company creation; entrepreneurial elements.

\section{INTRODUÇÃO}

O estudo do empreendedorismo vem ganhando cada vez mais destaque nas últimas décadas, emergindo como um campo de estudo acadêmico. Sua grande importância é atribuída ao fato de ser um mecanismo que movimenta e desenvolve a sociedade, permitindo a injeção de inovações em produtos, serviços e processos, o surgimento de novos mercados e propiciando geração de valor. Por outro lado, para analisarmos esses progressos e surgimentos de novos mercados, é necessário estudarmos o passo anterior que personifica o empreendedorismo na sociedade, isto é, a criação de empresas, buscando explicar: Quais os processos envolvidos nessa etapa? Quais variáveis devem ser abordadas? Como ocorre esse processo?

Gartner (1985) salienta que o processo de criação de empresas não é realizado instantaneamente, mas é uma construção incremental que possui aspecto complexo e multidimensional. Assim, de acordo com o autor, o processo irá variar entre os empreendedores e suas respectivas empresas, haja vista que suas ações sofrem influências internas e externas. Nesse contexto, o presente trabalho tem por objetivo analisar a criação de empresas, a fim de refletir sobre seu processo, bem como seus principais elementos que nele se encontram inseridos. No intuito de alcançar o objetivo proposto, foi realizada uma revisão bibliográfica com dados secundários de alguns dos principais autores do campo que trabalharam o tema proposto.

Em relação à estrutura, o presente trabalho está desenvolvido em três partes. O primeiro capítulo corresponde a esta parte introdutória, com a apresentação do tema, objetivo a ser alcançado e metodologia utilizada para tal. No segundo capítulo é exposto o processo de criação de empresas e os importantes elementos abrangidos por esse processo, tais como: oportunidade, alerta, risco, incerteza e contingência. E, por fim, são expostas na última parte algumas considerações finais que buscam concluir o trabalho realizado. 


\section{CRIAÇÃO DE EMPRESAS}

O estudo do processo de criação de empresas é um tema central ao campo de empreendedorismo, pois os efeitos da organização em seu início irão influenciar diretamente na sobrevivência dessas (BRUSH et al., 2008). Porém, os autores Liao e Welsch (2002); Katz e Gartner (1988); Brush et al. (2008) e Kimberly (1979) ressaltam que, apesar da crescente literatura nesta área, ainda há poucos estudos explorando esse assunto.

O processo de criação de empresas se refere à sequência temporal de eventos ou atividades que ocorrem para o empreendedor criar novos negócios (LIAO; WELSCH, 2002). Diversos autores o caracterizam como um processo dinâmico (BRUSH et al., 2008; GARTNER, 1985; LICHTENSTEIN et al., 2006). Brush et al. (2008) salientam que suas atividades, tais como, obtenção de recursos, desenvolvimento de produtos, busca por capital, entre outros, são realizadas em momentos e ordens diferentes. Por outro lado, Lichtenstein et al. (2006) afirmam que tal processo envolve múltiplos modos de atividades que acontecem simultaneamente e interdependente ao longo do tempo. Já Gartner (1985) acrescenta que esse processo é complexo e multidimensional, sendo construído de modo incremental.

Assim, para facilitar a compreensão de seu estudo, alguns autores definiram esse processo dividindo-o segundo dimensões ou propriedades que explicam o processo de criação de empresas, conforme pode ser visualizado no Quadro 1:

\begin{tabular}{|l|l|l|l|l|l|}
\hline \multicolumn{1}{|c|}{ AUTORES } & \multicolumn{5}{|c|}{ PROCESSO DE CRIAÇÃO DE EMPRESAS } \\
\hline $\begin{array}{l}\text { Gartner } \\
(1985)\end{array}$ & Indivíduo & Organização & Ambiente & Processo & \\
\hline $\begin{array}{l}\text { Katz e Gartner } \\
(1988)\end{array}$ & Intencionalidade & Recursos & Fronteira & Trocas & Trocas \\
\hline $\begin{array}{l}\text { Brush et al. } \\
(2008)\end{array}$ & Intencionalidade & Recursos & Fronteira & $\begin{array}{l}\text { Recursos } \\
\text { intangíveis }\end{array}$ \\
\hline $\begin{array}{l}\text { Kimberly } \\
(1979)\end{array}$ & Iniciação & Inovação & Institucionalização & & \\
\hline $\begin{array}{l}\text { Lichtenstein } \\
\text { et al. (2006) }\end{array}$ & Visão & Estratégico & Tático & & \\
\hline
\end{tabular}

Quadro 1 - Processo de criação de empresas.

Fonte: Elaborado pela autora.

Gartner (1985) sugere a utilização de uma estrutura composta de quatro dimensões, as quais são essenciais para criar uma nova organização. Para ele, nenhum processo de criação pode ser elaborado se quatro dimensões não forem identificadas 
(figura 1), são elas: (a) individual, a pessoa envolvida no processo de criar novas organizações, o empreendedor, com destaque para algumas características empreendedoras como lócus interno de controle; satisfação do trabalho; experiência anterior; propensão ao risco; otimismo; (b) organização, o tipo de empresa que será criada: varejo, atacado, serviço, manufatura, dentre outros; (c) ambiente, a situação que circunda e influencia a nova organização e abrange variáveis como disponibilidade de terras/locais, acessibilidade de transporte, influências governamentais, acessibilidade de fornecedores, clientes e novos mercados; (d) processo, as ações empreendidas pelo indivíduo para iniciar a nova organização, tais como, identificar oportunidades de negócio, acumular recursos, produzir os produtos, construir a organização, entre outros.

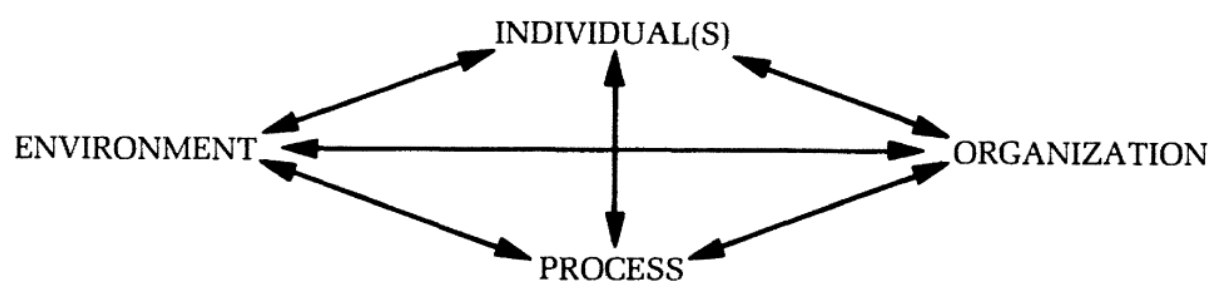

Figura 1 - Quadro para a descrição da criação de novas organizações.

Fonte: Gartner (1985, p. 698).

Em outro estudo, juntamente com Katz, os autores reforçam o processo interacional, afirmando que "as organizações emergem da interação dos agentes (indivíduos, parceiros, grupos) e do ambiente” (KATZ; GARTNER, 1988, p. 430). Dessa interação, os autores delinearam quatro propriedades de organizações emergentes, as quais, sendo tanto características estruturais quanto processuais, são a condição mínima necessária para identificar a existência de uma organização, a saber: (a) intencionalidade, o esforço proposital envolvido na criação de empresas, consiste na busca de informações pelo agente, as quais podem ser aplicadas no intuito de alcançar o objetivo de criar a nova organização; (b) recursos, componentes físicos necessários à criação de uma nova organização, mão de obra, capital financeiro, propriedade, equipamentos, entre outros; (c) fronteira, espaço delimitado da organização, suas áreas protegidas e/ou formalizadas que as separa de seu ambiente; (d) trocas, os ciclos de transações que podem ser através dos limites dos subsistemas dentro das organizações ou dos limites organizacionais com os indivíduos, ambientes ou outras organizações. É a mais dinâmica e volátil das quatro propriedades. 
Katz e Gartner (1988) salientam que essas quatro propriedades caracterizam uma organização completa e são necessárias para que essa exista. Assim, por meio dessas propriedades, os pesquisadores podem identificar antes as organizações, enquanto seu processo de criação. Porém, reforçam os autores, essas propriedades podem não aparecer simultaneamente. Além disso, o processo de criação de empresas é muito transitório, dado que uma organização emergente carece de inércia estrutural e os agentes podem tentar e, consequentemente, abandonar muitas formas organizacionais até um tipo específico se encaixar (KATZ; GARTNER, 1988). Assim, de acordo com os autores, identificar as organizações antes, em seu processo de criação, é valioso para determinar o sucesso ou o fracasso de diferentes estratégias organizacionais.

Nesse mesmo contexto, Brush et al. (2008) desenvolveram um estudo longitudinal para testar as quatro propriedades propostas por Katz e Gartner (1988). Os autores desenvolveram um conjunto de hipóteses para testar os princípios básicos das propriedades emergentes e realizaram uma pesquisa com empreendedores nascentes dos Estados Unidos, selecionados através do banco de dados do National Panel Study of Entrepreneurial Dynamics (PSED). Por meio dos resultados encontrados, os autores não só validaram, como também, propuseram uma extensão do modelo original proposto por Katz e Gartner (1988) separados em três áreas chaves:

\section{- Validação e extensão do modelo de Katz e Gartner (1988):}

Os resultados do estudo de Brush et al. (2008) mostraram forte suporte a importância das quatro propriedades. Entretanto, os autores ressalvaram que os recursos identificados por Katz e Gartner (1988) são inerentemente físicos e tangíveis e que é muito importante, também, considerar os recursos intangíveis, tais como, conhecimento cognitivo e capital social.

O conhecimento cognitivo influencia no modo como o empreendedor pensa em organizar, logo, irá afetar a estrutura da organização. Assim, é um recurso intangível que também deveria ser investigado em relação às propriedades organizacionais (BRUSH et al., 2008). Do mesmo modo, o capital social também deve ser explorado, pois ele representa as relações negociais e as relações com a família e com a comunidade que os empreendedores desenvolvem (BRUSH et al., 2008).

\section{- Cognição empreendedora:}

REMIPE- Revista de Micro e Pequenas Empresas e Empreendedorismo da Fatec Osasco 
Outro resultado encontrado no estudo de Brush et al. (2008) mostrou que, apesar de estudos na área cognitiva argumentarem que as intenções empreendedoras guiam as ações para novos empreendimentos, a intenção de abrir um novo negócio não precede necessariamente as outras três propriedades (trocas, recursos e fronteiras). Isso porque o processo de criar novas organizações não é um processo linear, assim as dimensões de intencionalidade são conduzidas de forma interativa e em conjunto com os demais processos.

\section{- Organização mais lenta é mais eficiente:}

Contrário às suas expectativas, Brush et al. (2008) identificaram que organizações nascentes, que levam mais tempo para acumular propriedades, tendem a continuar o esforço de organizar com mais frequência do que aquelas que passam pelo processo de organização mais rapidamente. Segundo os autores, o desenvolvimento organizacional deliberado e cuidadoso pode render mais conhecimento sólido sobre o negócio e levar às capacidades organizacionais que resultam em maior credibilidade aos olhos dos stakeholders.

Ainda de acordo com o quadro 1, John Kimberly (1979), por outro lado, estudou o processo de criação das organizações sobre os aspectos de iniciação, inovação e institucionalização. $\mathrm{O}$ último aspecto, institucionalização, não havia sido abordado pelos autores anteriormente citados, sendo um diferencial do estudo de Kimberly. Para tal, o autor realizou um estudo longitudinal do nascimento e primeiros desenvolvimentos de uma organização inovadora, no intuito de investigar o paradoxo que o sucesso gerado pela inovação no curto prazo, levava à incompatibilidade com os requisitos por sobrevivência a longo prazo, ao exigir sua institucionalização.

O estudo de Kimberly (1979) também focou o ambiente organizacional, pois segundo o autor, os fatores ambientais, sejam no âmbito político, econômico ou social, influenciam o processo organizacional, os processos de crescimento e desenvolvimento, bem como os resultados desses processos. Tal fato foi validado pelo seu estudo, pois o mesmo revelou que as restrições situacionais, juntamente com as características pessoais do empreendedor, levaram ao nascimento da organização e ao seu posterior sucesso.

Referente à variável de institucionalização, introduzido em seu estudo, o autor define como: "processo por meio de que novas normas, valores e estruturas são 
incorporados dentro de padrões já existentes" (KIMBERLY, 1979, p. 447). Esse processo é que fornece estabilidade e previsibilidade às relações sociais e permite que as organizações persistam. Kimberly (1979) ressalta que é preciso integrar alguns fatores institucionais às perspectivas da criação de empresas, como legislações, taxas de incentivo, regulamentos governamentais, lei de patente, entre outros, os quais são de grande significância ao processo. Outro ponto destacado pelo autor é referente às características do empreendedor. O autor argumenta que o desenvolvimento inicial da organização não pode ser entendido sem considerar também o conhecimento da ambição, visão, forças e fraquezas de seu empreendedor. A interação entre essas características com as restrições situacionais age como restrição na forma da organização nascente.

Por fim, Kimberly (1979) conclui, destacando que os processos de iniciação, inovação e institucionalização, apesar de terem sido analisados no processo de criação de uma empresa, não são domínios exclusivos das novas organizações. Muitas organizações passam por esses processos ao longo dos anos. O que difere é que a mudança em organizações existentes acontece em um contexto de cultura estabilizada, com regras, valores e procedimentos já institucionalizados.

Já Lichtenstein et al. (2006) estudaram o processo de criação de novas empresas sob outra ótica. Os autores desenvolveram um estudo longitudinal analisando o processo de organizações emergentes sob três modos de organizar: visão, estratégico e tático. O modo de visão foca na oportunidade de negócio que o empreendedor espera capitalizar e o conceito que ele organiza em volta dela. $\mathrm{O}$ segundo modo, estratégico, refere-se ao fluxo de decisões, ações e intervenções promulgadas pelo empreendedor, isto é, os movimentos tangíveis. E o modo tático envolve identificar o tempo em que eventos particulares de uma startup ocorreram.

A análise do estudo longitudinal revelou a emersão de uma nova visão para o empreendimento, uma mudança instantânea na organização estratégica e uma mudança pontual na organização tática. Essas mudanças simultâneas nos modos organizacionais foram definidas pelos autores como um evento emergente. $\mathrm{O}$ evento emergente é "uma mudança pontual e coordenada em múltiplos modos de organização empreendedora praticamente ao mesmo tempo, a qual gera um estado qualitativamente diferente, uma nova identidade, dentro do empreendimento nascente" (LICHTENSTEIN et al., 2006, p. 154). 
No modo de visão, os autores destacam o processo de reconhecimento da oportunidade como processo inicial desse modo e, complementam ser importante, também, investigar mudanças que o empreendedor pode ter realizado no conceito original da oportunidade, enfatizando que nem sempre a ideia inicial é a que acaba sendo implementada. À medida que a ideia vai sendo amadurecida podem ocorrer alterações. Já o segundo modo é dividido em quatro categorias de movimentos estratégicos da organização, a saber: movimentos organizacionais totais, conjunto completo de decisões e ações descrito pelo empreendedor; decisões estratégicas, questões que o empreendedor deve decidir; distrações de trabalho, responsabilidades com clientes e as obrigações do trabalho que tiram o tempo do empreendedor; investimentos pessoais pelo empreendedor (LICHTENSTEIN et al., 2006).

Quanto ao terceiro modo, o tático, estudos mostram que muitas de suas atividades são comuns aos empreendedores nascentes e representam ações diretas e específicas que levam ao objetivo da criação organizacional, tais como: elaboração do plano de negócio, organização do time do novo empreendimento, desenvolvimento de um protótipo, contratação de funcionários, primeira venda, entre outros (LICHTENSTEIN et al., 2006).

Assim, de um modo geral, pode-se definir o primeiro modo como amadurecimento da visão, o segundo como a definição de rumos e o terceiro como a implementação em si da visão. Além disso, dado a natureza altamente interdependente desse processo de organização empreendedora, espera-se que uma mudança emergente em um modo afete necessariamente todos os outros modos de organização e, que tais mudanças são quase simultâneas e pontuais. Dessa forma, essa sequência de mudanças reflete uma visão comportamental da criação do novo empreendimento, em que os recursos comportamentais tangíveis, que estão disponíveis para um empreendedor nascente, têm precedência sobre os aspectos cognitivos e orientados para objetivo do processo organizacional (LICHTENSTEIN et al., 2006).

Apesar das grandes contribuições das literaturas supracitadas, deve-se ressaltar que, como os estudos de Brush et al. (2008), Kimberly (1979) e Lichtenstein et al. (2006) se tratam de estudos de caso, não é possível generalizar os resultados obtidos, mas devem ser cuidadosamente validados antes de serem atribuídos a novos casos. 


\section{ELEMENTOS DA CRIAÇÃO DE EMPRESA}

A partir da reflexão das etapas do processo de criação de empresas, pode-se verificar que cada dimensão comporta várias atividades e lida com alguns elementos específicos. Entre os elementos mais citados na literatura, como componentes do processo de criação de um novo empreendimento, identificou-se como os principais: oportunidade, alerta, riscos, incertezas e contingências, abordados por diversos autores, conforme o quadro 2. Esse quadro permite uma visão geral no âmbito de empreendedorismo dos aspectos relacionados ao processo de criação de empresas e as principais abordagens do campo:

\begin{tabular}{|c|c|c|c|c|c|}
\hline ELEMENTOS & \multicolumn{5}{|c|}{ AUTORES } \\
\hline Oportunidade & $\begin{array}{l}\text { Shane e } \\
\text { Venkataram } \\
(2000)\end{array}$ & $\begin{array}{l}\text { Short et al. } \\
(2010)\end{array}$ & $\begin{array}{l}\text { Hansen et al. } \\
(2011)\end{array}$ & $\begin{array}{l}\text { Aldichvili et } \\
\text { al. (2003) }\end{array}$ & $\begin{array}{l}\text { Wood e } \\
\text { Mckinley } \\
(2010)\end{array}$ \\
\hline Alerta & $\begin{array}{l}\text { Tang, Kacmar e } \\
\text { Busenitz (2012) }\end{array}$ & $\begin{array}{l}\text { Kirzner } \\
(2009) \\
\end{array}$ & $\begin{array}{l}\text { Aldichvili et } \\
\text { al. }(2003)\end{array}$ & & \\
\hline Risco & $\begin{array}{l}\text { Janney e Dess } \\
(2006)\end{array}$ & $\begin{array}{l}\text { Gephart et } \\
\text { al. (2009) }\end{array}$ & & & \\
\hline Incerteza & $\begin{array}{l}\text { McMullen e } \\
\text { Shepherd (2006) }\end{array}$ & & & & \\
\hline Contingência & $\begin{array}{l}\text { Susan Harmeling } \\
\text { (2011) }\end{array}$ & & & & \\
\hline
\end{tabular}

Quadro 2 - Elementos da Criação de Empresas.

Fonte: Elaborado pela autora.

Após a publicação do artigo de Shane e Venkataraman (2000), The promise of entrepreneurship as a field of research, no qual os autores introduziram o elemento oportunidade no campo de empreendedorismo relacionando-a com a criação de futuros produtos e serviços, houve um grande interesse por esse elemento entre os pesquisadores do campo, tendo sido marcado pela publicação de diversos artigos, como: Hansen et al.(2011); Short et al. (2010); Tang, Kacmar e Busenitz (2012); Ardichvili et al. (2003); Chiasson e Sounders (2005); Wood e Mckinley (2010); Uesbasaran et al. (2009); entre outros.

A origem da discussão sobre oportunidades empreendedoras se encontra na Era Econômica, principalmente com a Escola Austríaca, em que não era suficiente se pensar em oportunidade apenas como uma ideia, mas era necessário também trabalhar, criar, transformar o sinal que o ambiente fornecia em forma de lucratividade, a oportunidade deveria ser lucrativa (LANDSTRÖM; BENNER, 2010). Sequencialmente, o enfoque de oportunidade, com os estudos de Shane e Venkataraman (2000), passou para uma visão 
mais individual. $\mathrm{O}$ empreendedorismo era visto como o encontro entre a oportunidade e o indivíduo. Esses seriam os responsáveis por identificar, avaliar e explorar as oportunidades, a fim de que elas possibilitem a criação de algo novo (mercado, produto, serviço, etc.).

Entretanto, estudiosos têm abordado a oportunidade empreendedora a partir de uma variedade de perspectivas teóricas, o que levou a inconsistentes definições conceituais e operacionais (HANSEN, et al., 2011). Sob a mesma ótica, Ardichvili et al. (2003) salientam que não há acordo entre pesquisadores do campo de empreendedorismo na maioria dos conceitos utilizados para definir oportunidade e, que ainda estamos longe de desenvolver uma teoria compreensiva de identificação e desenvolvimento de oportunidade.

De modo geral, duas abordagens dominam sobre a natureza da oportunidade. A primeira visão posiciona as oportunidades como sendo descobertas, isto é, elas surgem no ambiente a partir das mudanças. Estão "lá fora" e os indivíduos devem estar alertas para reconhecê-las. Já a segunda, concebe as oportunidades como sendo criadas por meio de um processo de ações empreendedoras (SHORT et al., 2010; HANSEN et al., 2011; ARDICHVILI et al., 2003). Nesse contexto, Short et al. (2010) e Hansen et al. (2011) desenvolveram um estudo bibliométrico sobre oportunidade, utilizando-se de diversos artigos publicados que abordaram o tema, mas utilizando fontes diferentes em cada pesquisa. O estudo de Hansen et al. (2011) focou mais no aspecto conceitual, enquanto Short et al. (2010) se aprofundaram mais nas análises.

Short et al. (2010) analisaram 68 artigos, no intuito de consolidar as realizações passadas e configurar um panorama para futuras pesquisas. Por meio dos resultados obtidos, os autores identificaram que a pesquisa construída sobre oportunidades tem sido teoricamente rica, evolvendo uma variedade de teorias, o que inclui a teoria da criação e da descoberta, anteriormente citadas, o que sugere uma grande promessa para a criação de uma teoria para oportunidade. Outrossim, os autores salientaram que a literatura sobre oportunidades enfoca três principais questões: a descoberta versus criação de oportunidade, a dinâmica temporal que cercam as oportunidades e a evolução de ideias e sonhos em oportunidades.

A primeira questão enfatiza que a oportunidade pode ser advinda de um processo de descoberta ou por meio de um processo construtivista, desenvolvido ao longo do tempo. A segundo questão se refere à duração da oportunidade, em que o 
tempo é crucial para identificar oportunidades. Finalmente, o último aspecto salienta que as oportunidades se formam a partir de ideias e sonhos, sendo que essas refletem aspirações empreendedoras, enquanto aquelas são oriundas do processo criativo (SHORT et al., 2010). Já no outro estudo, conduzido por Hansen et al. (2011), os autores analisaram 56 artigos publicados por Journals de Empreendedorismo e, baseados nos dados encontrados, desenvolveram seis definições de oportunidade como conceito (Quadro 3) e oito definições de oportunidades como processo (Quadro 4) na intenção de reduzir a fragmentação da literatura em oportunidade empreendedora.

Analisando o quadro 3, pode-se verificar que o conceito de oportunidade ainda é altamente fragmentado. As várias diferenças entre as definições expostas refletem diversas visões a respeito dos elementos importantes para oportunidade (HANSEN et al., 2011). Por exemplo, a figura do empreendedor é central para muitas, mas não todas as definições de oportunidade. Em algumas definições, a lucratividade é essencial para a oportunidade empreendedora, enquanto para outras, a ênfase é na geração de valor aos clientes. Observa-se, também, que algumas focam mais na oferta, enquanto em outros, o foco é na demanda.

\begin{tabular}{|c|l|}
\hline 1. & Uma oportunidade é a possibilidade de introduzir um novo produto no mercado para gerar lucro. \\
\hline 2. & $\begin{array}{l}\text { Uma oportunidade é uma situação em que empreendedores visualizam e criam novos meios para os } \\
\text { fins desejados. }\end{array}$ \\
\hline 3. & Uma oportunidade é uma ideia que se desenvolveu em uma forma de negócio. \\
\hline 4. & $\begin{array}{l}\text { Uma oportunidade é a percepção de um empreendedor sobre meios viáveis para obter/alcançar } \\
\text { benefícios. }\end{array}$ \\
\hline 5. & Uma oportunidade é uma habilidade de um empreendedor para criar a solução para um problema. \\
\hline 6. & Uma oportunidade é a possibilidade de servir clientes diferentemente e melhor. \\
\hline
\end{tabular}
Quadro 3 - Definições conceituais de oportunidade.

Fonte: Hansen et al. (2011, p. 292).

Em relação às oportunidades como um processo, analisando o quadro 4, pode-se observar que apesar dos termos reconhecimento, identificação e descoberta serem os mais frequentemente usados, os resultados expostos mostram que as definições dos diversos autores sugerem outros processos relacionados à oportunidade. Outrossim, pode-se identificar que cinco entre oito definiçõos tiveram uma forte tendência à próatividade ao invés de capacidade de resposta, por exemplo: desenvolvimento de oportunidade, varredura, combinação, criação, solução de problemas (HANSEN et al., 2011). 
1. Um processo cognitivo de reconhecimento de uma ideia e transformação dela em um conceito de negócio,

2. Um processo de varredura ou estar alerta.

3. Um processo cognitivo de combinar oferta e demanda.

4. Percepção de uma necessidade sentida.

5. Um processo criativo de geração de novas alternativas.

6. Um caso especial de solução de problemas.

7. Percepção de uma possibilidade de criar um negócio lucrativo ou melhorar um existente.

8. Um processo de construção social dentro de uma janela do tempo.

Quadro 4 - Definições conceituais de oportunidade como um processo.

Fonte: Hansen et al. (2011, p. 293).

Aldichvili et al. (2003) apresentam outra classificação do conceito de oportunidades. Os autores diferenciam quatro tipos de oportunidades baseadas em sua origem e no desenvolvimento, conforme poder ser visualizado na figura 2 . De acordo com essa, no quadrante superior esquerdo os problemas e as soluções são desconhecidos, representando o tipo de criatividade associada com artistas, sonhadores, inventores, os quais se interessam em mover o conhecimento para novas direções. No quadrante superior direito, os problemas são conhecidos, mas as soluções não. Ele descreve situações que ocorrem em que a solução do problema é estruturada e há busca por informações. O quadrante inferior esquerdo, no qual os problemas são desconhecidos, mas as soluções estão disponíveis, inclui os desafios de transferência de tecnologia, em que o desenvolvimento de oportunidades foca mais na aplicação do que no desenvolvimento de produtos e serviços. Por fim, no quadrante inferior direito tanto os problemas como as soluções são conhecidas, assim, o desenvolvimento de oportunidades envolve combinar os recursos com as necessidades para formar o negócio (ARDICHVILI et al., 2003).

A partir de sua conceitualização, anteriormente exposta, para o melhor entendimento das oportunidades, é fundamental analisar também seu processo de identificação. Uma variável antecedente à identificação de oportunidades é o alerta, variável de grande importância no campo de empreendedorismo. 


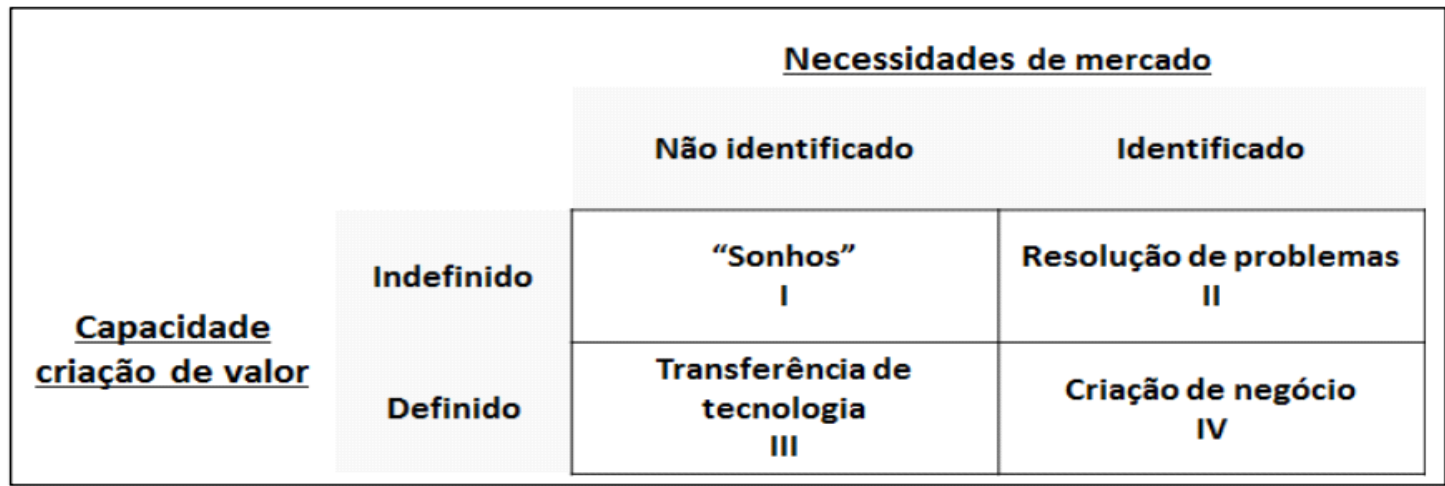

Figura 2 - Tipos de Oportunidades Fonte: Ardichvili et al. (2003 p. 117).

O conceito de alerta foi introduzido por Israel Kirzner (LANDSTRÖM; BENNER, 2010; TANG; KACMAR e BUSENITZ, 2012). Para ele, o mercado está em constante desequilíbrio e o empreendedor é aquele que direciona o processo a um equilíbrio. Para tal, ele deve estar alerta às imperfeições do mercado, por meio de informações sobre necessidade e recursos de diferentes atores e captar oportunidades que irão criar equilíbrio no mercado (LANDSTRÖM; BENNER, 2010). Assim, na visão de Kirzner (2009), a característica central para o empreendedorismo de sucesso não é a criatividade, mas o alerta para oportunidades já existentes, para mudanças ainda não percebidas. $\mathrm{O}$ conceito de alerta, então, é uma condição necessária para o sucesso da identificação de oportunidades. Ele auxilia no entendimento de como as ideias novas são identificadas e exploradas (TANG; KACMAR e BUSENITZ, 2012; ALDICHVILI ET al., 2003).

O alerta é o estado que permite os empreendedores a verem o que os outros não veem, fato que os distingue dos não empreendedores (KIRZNER, 2009). Segundo o autor, não precisa ser algo necessariamente novo. Nesse sentido, os empreendedores não precisam trazer/criar algo que seja novo, mas podem apenas identificar uma mudança no ambiente que, para outros indivíduos, passou despercebido, isto é, uma oportunidade que irá preencher uma lacuna presente no mercado e levá-lo a um equilíbrio. Dessa forma, o empreendedor, para Kirzner, opera como um observador de mudanças passivo. Ele não precisa ser essencialmente a figura ativa proposta, por exemplo, por Schumpeter (KIZRNER, 2009).

No entanto, antes de ocorrer o alerta empreendedor, existem alguns antecedentes importantes que irão influenciar o estado de alerta da oportunidade de negócios, são eles: traços pessoais, experiências e conhecimento anteriores, disposição pessoal, redes 
sociais, entre outros. Essa influência de elementos cognitivos foi apresentada pelos autores Tang, Kacmar e Busenitz (2012); Ardichvili et al. (2003) e Wood e Mckinley (2010) e podem ser visualizadas no Quadro 5:

\begin{tabular}{|l|c|c|c|}
\hline \multicolumn{1}{|c|}{ AUTORES } & \multicolumn{3}{|c|}{ ELEMENTOS COGNITIVOS } \\
\hline $\begin{array}{l}\text { Tang, Kacmar e } \\
\text { Busenitz (2012) }\end{array}$ & Disposição individual & $\begin{array}{c}\text { Treinamento e } \\
\text { experiência }\end{array}$ & Redes sociais \\
\hline Ardichvili et al. (2003) & $\begin{array}{c}\text { Traços de } \\
\text { personalidade }\end{array}$ & Redes sociais & Conhecimento prévio \\
\hline $\begin{array}{l}\text { Wood e Mckinley } \\
(2010)\end{array}$ & Laços sociais & Reputação & \\
\hline Janney e Dess (2006) & Aprendizado adquirido & Experiências vividas & Redes sociais \\
\hline
\end{tabular}

Quadro 5 - Elementos Cognitivos.

Fonte: Elaborado pela autora.

Baseados no trabalho de Kirzner, os pesquisadores Tang, Kacmar e Busenitz (2012) desenvolveram um modelo visando explicar a dinâmica do alerta ou, como ficar alerta. Esse envolve três elementos distintos: busca e varredura, associação e conexão, além de avaliação e julgamento. $\mathrm{O}$ modelo, exposto na figura 3 , inicia-se com o processo de busca e varredura, o qual auxilia o empreendedor a construir um domínio vasto de informações, abrangendo o conhecimento tácito e explícito. Essa etapa está intimamente ligada com a intenção, ou seja: quanto maior a intenção do indivíduo, mais ele irá buscar novas informações. Na sequência, é necessário que o empreendedor faça a associação e conexão entre as informações. Nessa etapa, os indivíduos distinguem quais informações são relevantes e quais devem ser desconsideradas, ademais procuram fazer associações e "ligações entre os pontos". Assim, enquanto a primeira etapa pode ser passiva ou ativa, essa etapa é proativa (TANG; KACMAR e BUSENITZ, 2012).

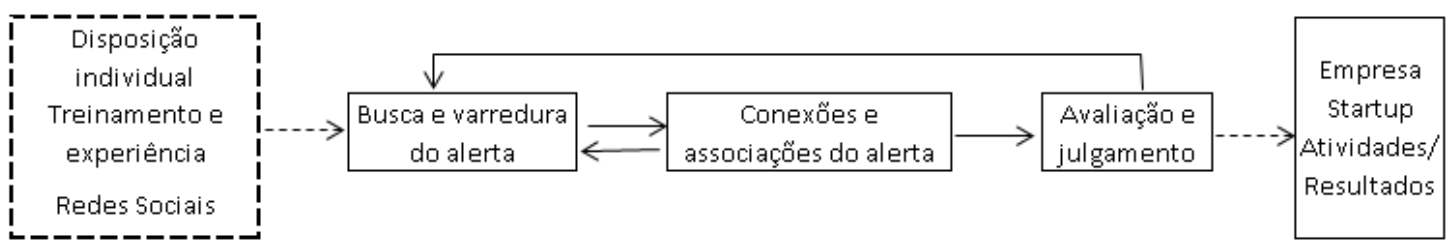

Figura 3 - Modelo de alerta empreendedor Fonte: Tang, Kacmar e Busenitz (2012, p. 80).

Por fim, é necessário ao empreendedor avaliar e julgar a oportunidade entre as múltiplas possibilidades. Essa fase permite que o empreendedor julgue o conteúdo da 
REMIPE

nova informação, filtre as informações que não são essenciais e faça uma avaliação se a nova informação reflete alguma oportunidade de negócio potencial. Ao fazer isso, o empreendedor aumenta sua percepção da situação. A avaliação e julgamento compreende a atenção da oportunidade pela terceira pessoa, ou seja, por uma pessoa externa, e a avaliação da oportunidade pela própria pessoa ou primeira pessoa. O primeiro estágio acontece quando um indivíduo acredita que a oportunidade existe, mas é para outra pessoa e, já no segundo estágio, o empreendedor decide se é uma oportunidade para si (TANG; KACMAR e BUSENITZ, 2012).

Conforme pode ser observado pelas flechas na figura 3, o modelo de Tang, Kacmar e Busenitz é dinâmico: uma vez que os pontos identificados foram conectados, os indivíduos podem precisar fazer uma busca e varredura no ambiente novamente, a fim de clarear ou explorar a utilidade das novas informações relacionadas. O mesmo pode ocorrer na fase de avaliação e julgamento.

Debatido sobre o alerta, o processo de identificação de oportunidades foi abrangido por autores como Ardichvili et al. (2003) e Wood e Mckinley (2010). O modelo de Ardichvili et al. (2003), exposto na figura 4, parte do pressuposto que elementos cognitivos, tais como, traços de personalidade, redes sociais e conhecimento prévio auxiliam na capacidade de alerta empreendedor, o qual, por sua vez, tem influência na percepção, descoberta e criação da oportunidade. Na sequência, a ideia é desenvolvida e avaliada e, como resultado da avaliação, a ideia pode ser implementada, na criação de um empreendimento, ou abandonada. 


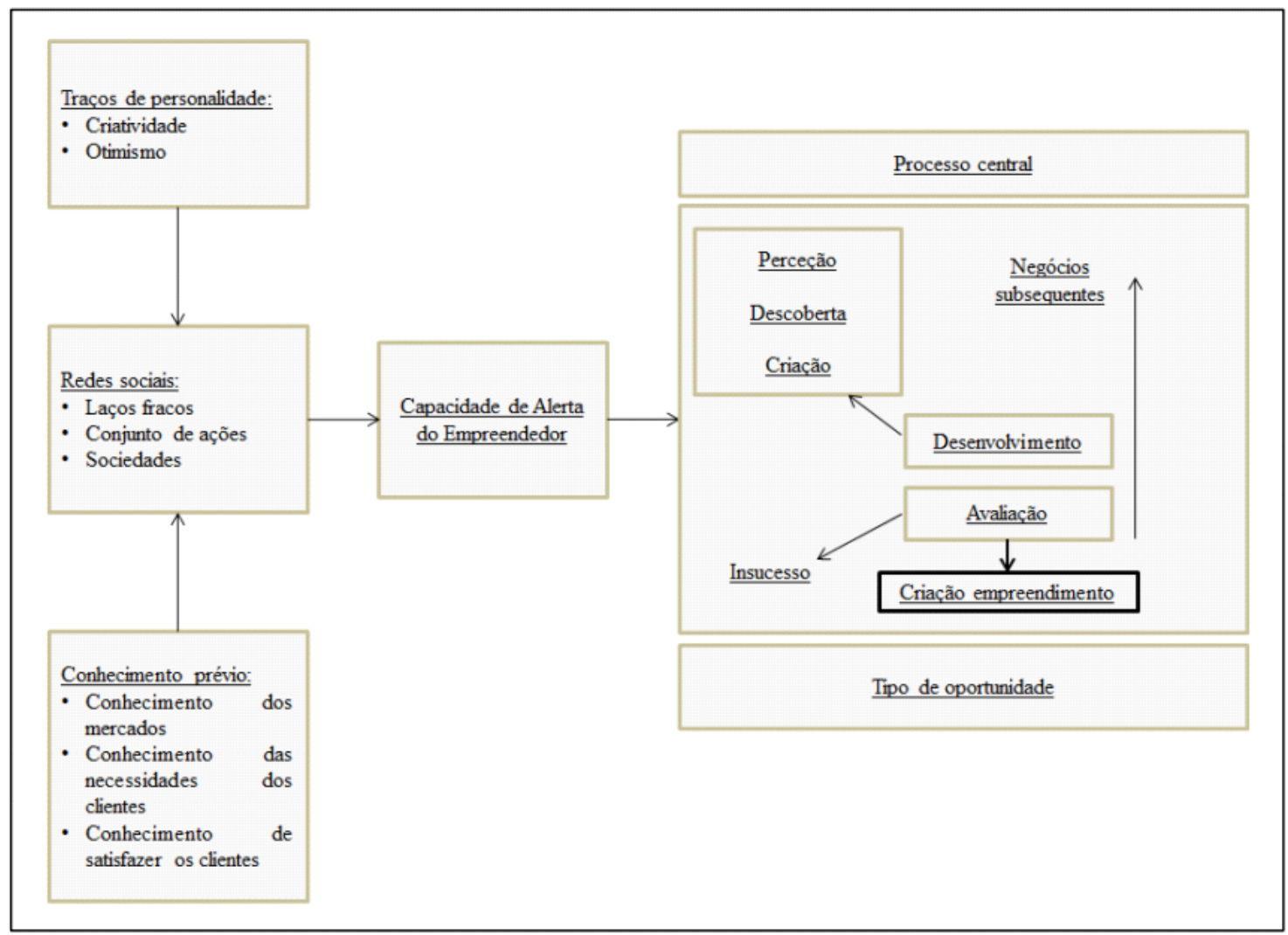

Figura 4 - Modelo de identificação de oportunidades

Fonte: Ardichvili et al. (2003, p. 118).

Wood e Mckinley (2010), com base numa perspectiva construtivista, desenvolveram um modelo de produção de oportunidade empreendedora (figura 5). Os autores salientam que o processo de produção de oportunidade envolve vários estágios, incluindo a conceituação de uma ideia de oportunidade por um empreendedor, a objetivação dessa oportunidade e a implementação da oportunidade em uma nova empresa. 


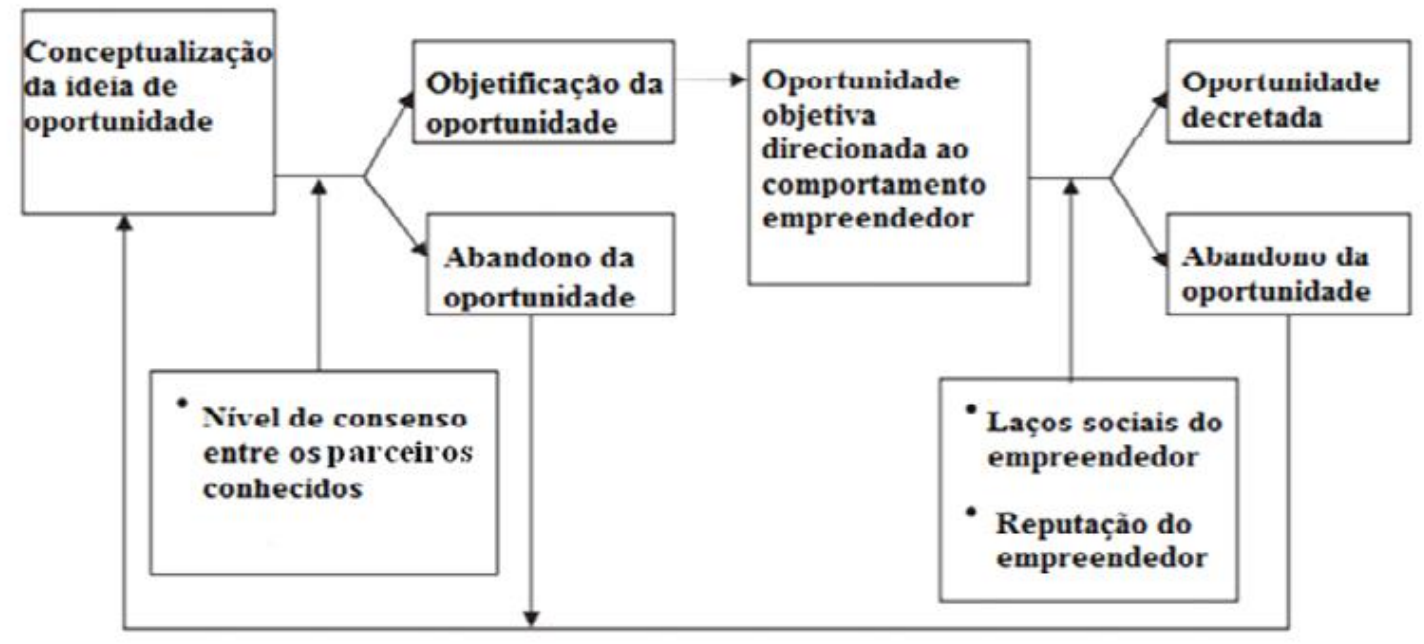

Reconstrução

Figura 5 - Modelo de produção de oportunidade empreendedora

Fonte: Wood e Mckinley (2010, p.71).

Entretanto, ressalvam os autores que nem todas as oportunidades sobrevivem a todo o processo, isto é, elas podem ser abandonadas na fase de objetivação, por terem sido percebidas como inadequadas ou, na passagem da fase de objetivação para implementação. Uma explicação possível para esse último abandono seria a insuficiência de recursos necessários. Porém, quando as ideias são abandonadas, elas podem passar por um processo de reconstrução, em que serão analisadas novamente e, se possível, alteradas em uma nova oportunidade. Wood e Mckinley (2010) também atribuíram a influência de elementos cognitivos no processo de identificação de oportunidade. Segundo os autores, laços sociais e reputação não são apenas fatores importantes que facilitam a implementação das oportunidades emergentes como também são definitivamente dignos de nota. A introdução da variável reputação foi uma novidade do modelo de Wood e Mckinley (2010), haja vista que foi a primeira vez que foi considerado.

Com base em todo o referencial apresentado, procurou-se agrupar os elementos discutidos em um modelo a fim de permitir uma melhor compreensão do processo de identificação da oportunidade. Esse modelo é apresentado na figura 6.

Adicionalmente, outra variável apontada com grande importância no campo de empreendedorismo é o risco. Intimamente vinculado com a incerteza, o risco foi objeto de vários estudos acadêmicos. Janney e Dess (2006) conceituaram o risco em três categorias distintas: o risco como variância, como downsideloss e como oportunidade. $\mathrm{O}$ risco como variância está mais restrito às perdas financeiras, refere-se aos resultados 
REMIPE

potenciais que podem ser tanto bons quanto maus. Quanto ao risco de downsideloss e oportunidade, ambos focam nos resultados das decisões empreendedoras, porém o downsideloss enfatiza as perdas, ou seja, quanto o empreendedor está disposto ao perder, enquanto o risco de oportunidade enfoca os ganhos, isto é, qual o ganho máximo que se pode ter.

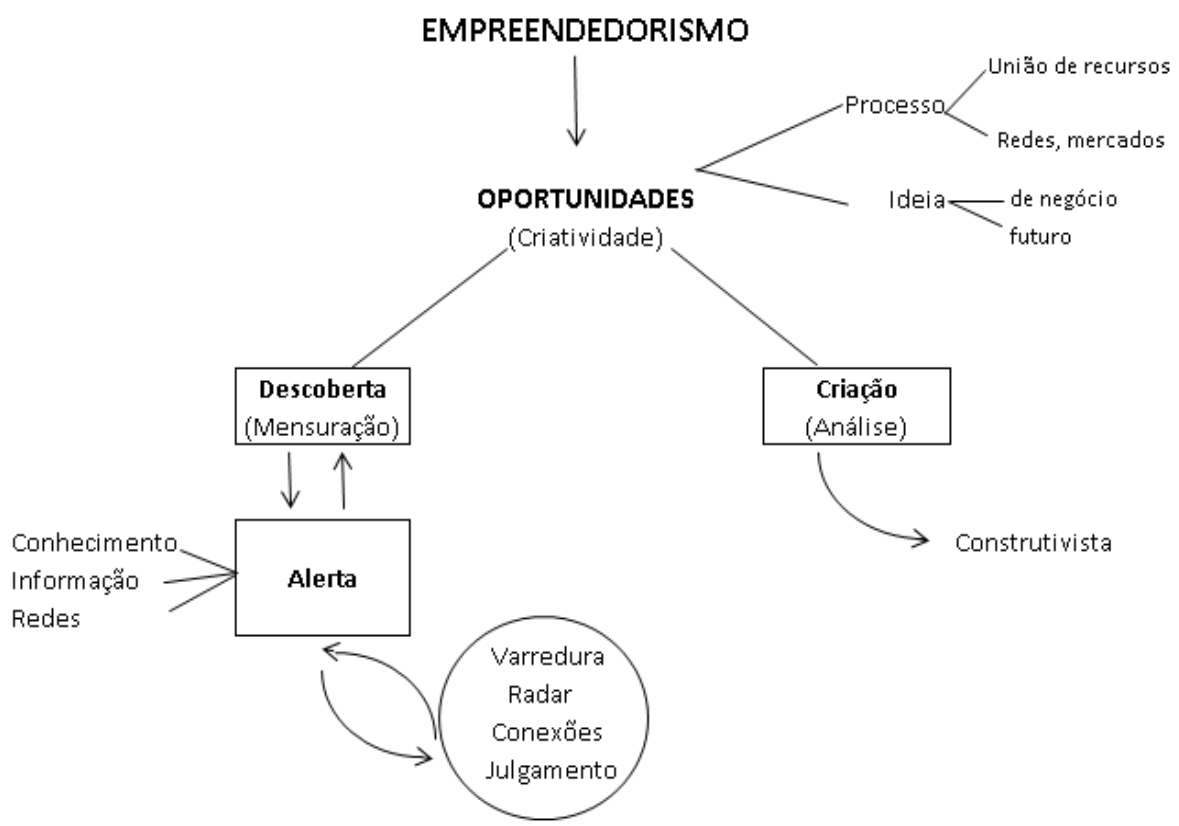

Figura 6 - Modelo de identificação de oportunidades

Fonte: Elaborado pela autora com base na literatura.

Assim como os autores Tang, Kacmar e Busenitz (2012); Ardichvili et al. (2003) e Wood e Mckinley (2010) salientaram a influência de elementos cognitivos no processo de identificação da oportunidade. Janney e Dess (2006) também ressaltam a importância de alguns fatores cognitivos, tais como, conhecimento e experiência anterior na percepção do risco. Segundo os autores, o aprendizado adquirido, as experiências vividas e as redes sociais auxiliam o empreendedor tanto a perceber o risco, como a diminuir seu impacto, dado que esses elementos facilitam a obtenção de recursos, o suporte de stakeholders, a legitimação do negócio, além de fornecerem uma bagagem maior de conhecimentos, os quais serão de grande utilidade no momento de lidar com o risco.

Outro destaque no estudo dos autores refere-se à dualidade do risco e à relação entre empreendedor e investidor. Janney e Dess (2006) expuseram que o investidor busca uma segurança para diminuir o risco de seu investimento. Assim, ele precisa de informações mais precisas para avaliar a potencialidade do negócio. Por outro lado, o 
empreendedor não pode propiciar toda essa segurança ao investidor, pois se ele fornece todas as informações que o investidor deseja, o risco de ter sua ideia "roubada" aumenta. Mas, por outro lado, ele também precisa dos recursos/capital do investidor para conseguir implantar sua ideia.

Gephart et al. (2009), por outro lado, já trabalharam a variável risco sob o enfoque de diferentes contextos, abordando a noção de risco inserido na sociedade. Os autores trabalharam o contexto cognitivista, cultural-simbólico, a sociedade de risco, a governabilidade, acidentes normais e o sensemaking. Na visão cognitivista, criticada pelos autores por estar aquém de sua noção, o risco é concebido como um fenômeno objetivo. Ele existe numa forma real no mundo e sua realidade pode ser acessada determinando a probabilidade de um evento adverso multiplicado por sua magnitude e consequências severas.

Ao contrário, para a abordagem cultural-simbólica, o risco não é totalmente objetivo e não é estático, ele é constantemente construído e possui uma dimensão coletiva, isto é, o risco irá impactar outros grupos. Assim, essa abordagem olha para o social, ou seja, o risco existe independente do indivíduo. Para eles, o risco é a instabilidade, é aquilo que desequilibra a ordem social. Por outro lado, na visão da sociedade do risco, apesar de esse ter uma amplitude coletiva, isto é, ele é para todos, o olhar do risco, nesse contexto, é como uma consequência para o indivíduo: o seu efeito impacta na dimensão individual (GEPHART et al., 2009).

A governabilidade é uma abordagem neoliberalista. Nessa visão, o risco é criado por meio dos discursos, estratégias e práticas institucionais e, toma forma como uma racionalidade calculada. Assim, o risco é transgredir essas regulações e ele nunca acaba. Logo, os indivíduos constantemente devem se autorregular a fim de evitar os riscos. O quinto enfoque, acidentes-normais, enfatiza mais o papel da tecnologia, em que o risco é visto como uma concepção da limitação humana em prever acidentes normais, em função da complexidade da tecnologia. Por fim, o último contexto de sensemaking se refere à construção pela soma das subjetividades, ou seja, as verdades compartilhadas entre os sujeitos. Nesse sentido, o risco é visto como a disruptura do sensemaking, quando há uma ausência de significados, haja vista que o sensemaking fornece segurança e amparo aos sujeitos. Assim, a ameaça de se perder isso configura o risco (GEPHART et al., 2009). 
A variável incerteza vinculada ao risco foi abordada no estudo de McMullen e Shepherd (2006). Em seu artigo, Entrepreneurial action and the role of uncertainty in the theory of the entrepreneur, os autores enfatizaram o papel da incerteza enquanto forma de inibir ou favorecer a ação. A incerteza é categorizada em três tipos: state uncertainty, usada para denotar quando os administradores percebem que o ambiente é imprevisível, refere-se à questão “o que acontece 'lá fora'?”; effect uncertainty, trata-se da dificuldade em prever qual será a natureza do impacto que o futuro do ambiente ou de uma mudança ambiental irá causar na organização, "como isto irá me afetar?" e response uncertainty, refere-se à falta de conhecimento das opções de respostas perante a incerteza, o que o empreendedor irá fazer a respeito, e a impossibilidade de prever quais consequências a ação adotada trará, “o que eu farei a respeito?”.

A reflexão dessas questões irá levar os indivíduos a enxergarem o risco e, conforme também exposto no trabalho de Tang; Kacmar e Busenitz (2012), a terem a percepção da oportunidade como sendo para o outro (terceira pessoa) ou para si próprio (primeira pessoa). Inicialmente, o sujeito identifica a oportunidade como sendo para o outro e depois passa a enxergar para si. Nesse interim, a incerteza é vista como a distância entre as duas pessoas, entre a oportunidade para o outro ou para si. A partir do momento em que o indivíduo visualiza a oportunidade como sendo para si, a incerteza acaba (MCMULLEN; SHEPHERD, 2006).

Outrossim, a incerteza também é vista como a possibilidade de interromper ou inibir a ação. $O$ indivíduo deve se questionar se ele acredita que os benefícios da oportunidade justificam enfrentar as incertezas percebidas. Assim, pode-se concluir que a ação empreendedora requer uma alta tolerância à incerteza (MCMULLEN; SHEPHERD, 2006). Finalmente, abordando a variável contingência, Susan Harmeling (2011), em seu artigo Contingency as an entrepreneurial resource: how private obsession fulfills public need, enfatiza o papel da contingência nas oportunidades e evidencia que é importante levar em conta os riscos e as incertezas. Também é essencial considerar a contingência no processo empreendedor.

A contingência no estudo de Harmeling (2011) é ilustrada enquanto recurso. Ela se torna um recurso nas mãos do tomador de decisão, permitindo que ele se torne um agente ativo de mudança no mundo. Logo, a contingência por si só não é interessante, pois ela depende do autor. O que importa é a resposta que o indivíduo emite diante dessa contingência, as quais irão possibilitar a criação de artefatos. Harmeling (2011) 
classifica dois tipos de contingência, a pessoal (agente) e a histórica (contexto) e, introduz a contingência como o encontro entre ambas. É a partir da interação entre agente e contexto que ocorre o processo empreendedor. Assim, não existe mais a dicotomia entre indivíduo e contexto, mas a interação entre ambos. A resposta à contingência permite que a obsessão privada satisfaça a necessidade pública. A autora ilustra essa perspectiva por meio de histórias de alguns empreendedores, os quais, estando imersos em um contexto geral, isto é, na contingência história, e ao se utilizarem de um problema ou situação pessoal, ou seja, tomarem a contingência pessoal como oportunidade, eles criaram novos artefatos. Portanto, compreender tanto a contingência pessoal quanto a histórica é fundamental para o entendimento do processo de criação de valor e de como os mercados emergem (HARMELING, 2011).

Outrossim, Harmeling (2011) também introduz a questão de tempo em seu trabalho. Segundo a autora, a contingência tem um período de duração e, com o passar do tempo, sua aplicabilidade pode ser alterada. Logo, os empreendedores devem aproveitar enquanto a "janela" ainda não se fechou, pois algo que era possível ontem pode não ser mais hoje e vice-versa. Questão também abordada por Short et al. (2010).

\section{CONSIDERAÇÕES FINAIS}

O presente trabalho abordou a discussão dos aspectos da criação de empresas e dos principais elementos envolvidos no processo. Com base no referencial exposto, pôde-se observar que, apesar de o processo de criação ser um tema de grande importância no campo de empreendedorismo, proporcionando geração de valor ao mercado, o mesmo, assim como seu campo de um modo geral, apresenta-se altamente fragmentado. Abordagens divergentes e independentes sobre o mesmo assunto contribuem para essa fragmentação. Tal cenário pôde ser visto, por exemplo, nos estudos bibliométricos acerca de oportunidade.

Além disso, é valido destacar a alta dinamicidade do processo de criação de empresas. O mesmo é marcado pela interação de suas variáveis que vão moldando e sendo moldadas pelos indivíduos durante todo o processo. Outrossim, pode-se observar também a crescente menção e estudo da influência dos elementos cognitivos na criação de novos empreendimentos, seja para facilitar o estado de alerta na descoberta da oportunidade, uma das visões dominantes, ou permitir o êxito na criação de 
oportunidades a partir de transformações do ambiente, segunda visão dominante. Logo, é imprescindível considerar esses elementos ao examinar as ações empreendedoras no intuito de se evitar lacunas ou limitações no estudo.

Por fim, pode-se concluir que os estudos e pesquisas realizadas nessa área são de suma importância ao campo de empreendedorismo, auxiliando para a compreensão do processo e dos impactos das variáveis envolventes. Assim, a partir dos resultados já conquistados, torna-se mais necessário para as próximas pesquisas a busca por uma maior coesão dos estudos, a fim de neutralizar as diversas fragmentações do campo e erradicar as lacunas existentes.

\section{REFERÊNCIAS}

ARDICHVILI, Alexander et al. A theory of entrepreneurial opportunity identification and development. Journal of Business Venturing, v. 18, p. 105-123, 2003.

BRUSH, Candida G. et al. Properties of emerging organizations: an empirical test. Journal of Business Venturing, v.23, p.547-566, 2008.

CHIASSON, Mike N.; SOUNDERS, Chad. Reconciling diverse approaches to opportunity research using the structuration theory. Journal of Business Venturing, v.20, p.747-767, 2005.

GARTNER, William B. A conceptual framework for describing the phenomenon of new venture. Academy of Management Journal, v.10, n.4, p. 696-706, 1985.

GEPHART, Robert P. et al. Organizations and risk in late modernity. Organization Studies, v. 30, p. 141-155, 2009.

JANNEY, Jay J.; DESS, Gregory, G. The risk concept for entrepreneurs reconsidered: new challenges to the conventional wisdom. Journal of Business Venturing, v.21, p.385-400, 2006.

HANSEN, David J. et al. Defragmenting definitions of entrepreneurial opportunity. Journal of Small Business Management, v. 49, p. 283-304, 2010.

ARMELING, Susan. Contingency as an entrepreneurial resource: how private obsession fulfills public need. Journal of Business Venturing, v. 26, p. 293-305, 2011.

KATZ, J; GARTNER, W. Properties of Emerging Organizations. Academy of Management Review, v. 3, n. 3, p. 429-441, 1988.

KIMBERLEY, J, R. Issues in the creation of organization: initiation, innovation and institutionalization. Academy of Management Journal, v. 22, n. 3, p. 437-457, 1979. 
KIRZNER, Israel M. The alert and creative entrepreneur: a clarification. Small Business Economics, v. 32, p. 145-152, 2009.

LANDSTRÖM, Hans; BENNER, Mats. Entrepreneurship research: a history of scholarly migration. In: LANDSTRÖM, H.; LOHRKE, F. Historical foundations of entrepreneurship research. Great Britain: Edward Edgar, 2010.

LIAO, Jianwen; WELSCH, Harold. The temporal patterns of venture creation process: an exploratory study. In: BYGRAVE, W. D. et al. (Ed.). Frontiers of Entrepreneurship Research 2002. Wellesley: Babson College, 2002.

LICHTENSTEIN, Benyamin B. et al. Measuring emergence in the dynamics of new venture creation. Journal of Business Venturing, v. 21, p. 153-175, 2006.

MCMULLEN, Jeffery S.; SHEPHERD, Dean A. Entrepreneurial action and the role of uncertainty in the theory of the entrepreneur. Academy of Management Review, v. 31, n. 1, p. 132-152, 2006.

SHANE, S.; VENKATARAMAN, S. The promise of entrepreneurship as a field of research. Academy of Management Review, v. 25, n. 1, p. 217-226, 2000.

SHORT, Jeremy C. et al. The concept of "opportunity" in entrepreneurship research: past accomplishments and futures challenges. Journal of Management, v. 36, n 1, p. 40-65, 2010.

TANG, Jintong; KACMAR, K. Michele; BUSENITZ, Lowell. Entrepreneurial alertness in the pursuit of new opportunities. Journal of Business Venturing, v. 27, p. 77-94, 2012.

UESBASARAN, Deniz et al. The extent and nature of opportunity identification by experienced entrepreneurs. Journal of Business Venturing, v. 24, p. 99-115, 2009.

WOOD, Matthew; MCKINLEY, William. The production of entrepreneurial opportunity: aconstructivist perspective. Strategic Entrepreneurship Journal, v. 4, p. 66-84, 2010. 